\title{
Immunoadsorption Improves Remission Rates of Patients with Antineutrophil Cytoplasmic Antibody-Associated Vasculitis and Severe Kidney Involvement
}

\author{
Xiaoxin Chu ${ }^{\mathrm{a}}$ Yu Hong ${ }^{\mathrm{a}}$ Yuxi Wang ${ }^{\mathrm{a}}$ Chong Yu ${ }^{\mathrm{a}}$ Lisheng Wang $^{\mathrm{a}}$ Hui Tong ${ }^{\mathrm{a}}$ \\ Jianjun Yan ${ }^{a}$ Zhonghua Zhang ${ }^{a} G$ Gang $X^{a}{ }^{a}$ Ying Yao $^{a}$ b Rui Zeng ${ }^{a}$ \\ aDepartment of Nephrology, Tongji Hospital, Tongji Medical College, Huazhong University of Science and \\ Technology, Wuhan, China; ' Department of Nutrition, Tongji Hospital, Tongji Medical College, Huazhong University \\ of Science and Technology, Wuhan, China
}

\section{Keywords}

Immunoadsorption - Antineutrophil cytoplasmic antibodyassociated vasculitis · Remission - End-stage kidney disease . Death

\begin{abstract}
Introduction: The role of plasma exchange in treatment of antineutrophil cytoplasmic antibody (ANCA)-associated vasculitis (AAV) with severe kidney involvement is controversial. It is urgent to find effective treatments to improve prognosis of AAV patients. In this retrospective study, the outcomes of immunoadsorption (IA) onto protein A in AAV patients with severe kidney involvement were evaluated. Methods: Clinical data of 60 patients with AAV and severe kidney involvement were analyzed. Patients received cyclophosphamide or rituximab for remission induction, among which 16 were additionally treated with IA. Remission, end-stage kidney disease (ESKD), death, and relapse were compared. Results: Of 60 patients, 56 patients (93.3\%) were positive for myeloperoxidase (MPO)-ANCA. At diagnosis, the estimated glomerular filtration rate and Birmingham Vasculitis Activity
\end{abstract}

Score (BVAS) was $13.0(7.7,18.7) \mathrm{mL} / \mathrm{min} / 1.73 \mathrm{~m}^{2}$ and $11.1 \pm$ 3.4 , respectively. After 3-17 days (mean 10.4 days) of induction treatment, the disease activity decreased more obviously in the IA group $(p=0.022)$ than the control group. IA showed superior over standard regimen in clearance of MPO-ANCA within 3-31 days (median 11 days) after treatment $(78.4 \%$ vs. $9.3 \%, p=0.005)$. After a median follow-up of 20.2 months, remission was achieved more quickly ( $p=$ 0.035 ) and higher (hazard ratio $(\mathrm{HR})=2.3,95 \%$ confidence interval (CI): $1.1 \sim 7.2, p=0.033$ ) in the IA group than the control group. IA therapy showed an advantage in reducing death ( $\mathrm{HR}=0.2,95 \% \mathrm{Cl}: 0.1 \sim 0.9, p=0.032$ ). There was no difference in developing into ESKD in both groups (HR=0.7, $95 \% \mathrm{Cl}: 0.3 \sim 2.0, p=0.504)$. Multivariate Cox regression analysis indicated that early-stage remission was an independent predictor for ESKD ( $\mathrm{HR}=0.03,95 \% \mathrm{Cl}: 0.003 \sim 0.25, p=$ $0.001)$ and death ( $\mathrm{HR}=0.07,95 \% \mathrm{Cl}: 0.01 \sim 0.51, p=0.009)$. Conclusion: IA treatment induces quicker and higher remission and lower mortality in AAV patients with severe kidney involvement. The early remission independently predicts the outcomes for these patients.

(c) 2021 The Author(s).

Published by S. Karger AG, Basel
(C) 2021 The Author(s)

Published by S. Karger AG, Basel

This is an Open Access article licensed under the Creative Commons Attribution-NonCommercial-4.0 International License (CC BY-NC) (http://www.karger.com/Services/OpenAccessLicense), applicable to the online version of the article only. Usage and distribution for commercial purposes requires written permission.
Correspondence to:

Ying Yao, yaoyingkk@126.com

Rui Zeng, zengr126@126.com 


\section{Introduction}

Antineutrophil cytoplasmic antibody (ANCA)-associated vasculitis (AAV) is a multisystem autoimmune disease characterized by inflammation of small- and medium-sized blood vessels and circulating autoantibodies to the leukocyte proteinase 3 or myeloperoxidase (MPO) [1-3]. AAV is prone to be present with severe kidney diseases and a clinical syndrome of rapidly progressive glomerulonephritis with poor prognosis $[4,5]$.

The therapy for AAV with kidney involvement has greatly improved in recent years. The use of cyclophosphamide (CYC) and/or rituximab (RTX) plus glucocorticoid (GC) effectively induces remission in the majority of cases [1, 6-14]. However, AAV patients with impaired renal function at diagnosis have a 5.42 -fold increase in mortality compared with patients without kidney involvement [15]. A 5-year retrospective study showed that the cumulative renal survival rate at 5 years was only $50 \%$ for patients with end-stage renal failure [16]. Base on the pathogenesis of AAV, rapid removal of pathogenic autoantibodies and inflammatory mediators may potentially abolish the inciting cause of AAV and benefit patients [3, $17,18]$. The MEPEX trial showed that among AAV patients with serum creatinine $(\mathrm{SCr})>500 \mu \mathrm{mol} / \mathrm{L}$, the risk of progression to end-stage kidney disease (ESKD) was reduced by $24 \%$ at 1 year in patients with plasma exchange (PLEX) treatment [19]. Nevertheless, the longterm result of the MEPEX trial did not show any improvement in ESKD or death after a median follow-up of 3.95 years [20]. The PEXIVAS trial [21,22] either had not observed any benefit of PLEX in AAV patients with the estimated glomerular filtration rate (eGFR) $<50 \mathrm{~mL} /$ $\min / 1.73 \mathrm{~m}^{2}$ or alveolar hemorrhage. A retrospective study of AAV patients with an eGFR $<30 \mathrm{~mL} / \mathrm{min} / 1.73$ $\mathrm{m}^{2}$ conducted at the Mayo Clinic showed similar results, consistent with the PEXIVAS trial [4]. Therefore, to identify effective approaches to improve outcomes of AAV patients with kidney involvement is urgently needed.

Immunoadsorption (IA) is a mature technique that specifically removes pathogenic antibodies without supplementation of plasma or albumin. IA theoretically avoids the loss of protective proteins and the risk of allergy and disease transmission due to transfusion of the blood product [23, 24]. Palmer et al. [25] found that IA combined with GC and CYC benefited AAV patients with rapidly progressive glomerulonephritis. After treatment, the titers of ANCA significantly decreased, and the renal function improved within 3-7 days. Esnault et al. [26] also reported that IA specifically cleared immuno- globulin (Ig) G (IgG) antibodies in 2 AAV patients and rapidly reduced the disease activity and induced remission. No observations have reported any serious side effects with IA treatment $[25,27]$.

However, controlled studies of IA in AAV patients with severe kidney diseases are still lacking. In this retrospective study, we evaluated whether additional IA therapy induced better outcomes than GC combined with immunosuppressant therapy alone.

\section{Materials and Methods}

\section{Patients}

In this single-center retrospective study, 179 patients meeting AAV vasculitis diagnostic criteria [28], older than 18 years in the Department of Nephrology at Tongji Hospital in Wuhan, China, from December 1, 2016, to January 20, 2020, were screened. Exclusion criteria were as follows: (1) maintenance hemodialysis > 3 months; (2) disease course $>12$ months; (3) treated with PLEX or double-filtration plasmapheresis; (4) combined with other primary or secondary glomerular diseases, such as anti-glomerular basement membrane antibody glomerulonephritis and systemic lupus erythematosus; (5) with tumor; (6) lost to follow-up; and (7) the eGFR estimated by the CKD-EPI equation [29] $>60 \mathrm{~mL} / \mathrm{min} / 1.73 \mathrm{~m}^{2}$. Eventually, 60 patients, including 16 patients treated with additional IA and 44 patients treated with standard regimen, were included (online suppl. Fig. 1; see www.karger.com/doi/10.1159/000519608 for all online suppl. material). The date of starting treatment was registered to calculate the time-events outcome (Fig. 1). All patients were followed up to death or until January 20, 2021.

\section{Treatment}

According to patients' conditions, patients received GC combined with CYC or RTX as induction remission therapy except for contraindications, such as severe infection. The dosage and reduction of oral GC depended on the attending physicians by referring to the initial standard of $1 \mathrm{mg} / \mathrm{kg} /$ day. Some patients received pulse methylprednisolone therapy, 500-1,000 mg/day for 3-5 days. CYC was given intravenously at 400-1,000 mg every month. RTX was given intravenously at $100 \mathrm{mg}$ per month for 3 months, then $100 \mathrm{mg}$ every 3 months. When CYC failed to induce remission, RTX was applied instead. Maintenance regimens, such as azathioprine (50-100 mg/day), mycophenolate mofetil (0.5-1.0 g/day), and leflunomide (5-10 mg/day), were determined by the physicians.

IA was performed by an adsorption column with genetic engineering recombinant protein A (KCIA08, Guangzhou Koncen Bioscience Co., Ltd., Guangzhou, China) and perfusion apparatus (JF-800A, Jafron Biomedical Co., Ltd., Zhuhai, China) after separating the plasma and blood cells through a plasma separator (Plasmaflo-OP08W, Asahi Kasei Medical, Tokyo, Japan). IA was administered continuously or intermittently within 14 days. The $6,000 \mathrm{~mL}$ plasma volume was processed within 10 cycles per session. The frequency of IA treatments (no >10) was determined based on changes in the ANCA titers, renal function, and the general conditions of patients and decided by the attending physicians. 


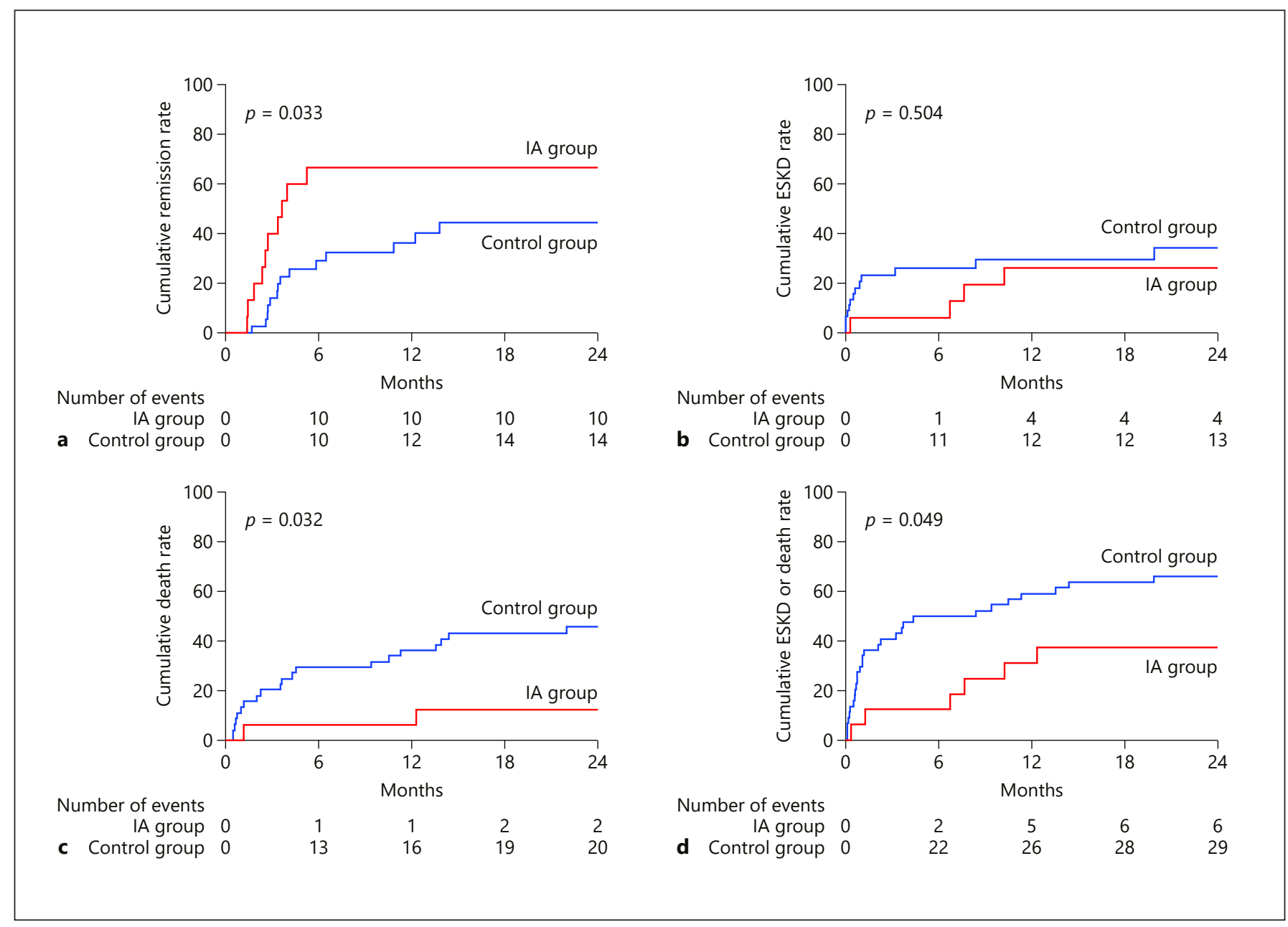

Fig. 1. Kaplan-Meier curves for remission (a), ESKD (b), death (c), and ESKD or death (d). There were 16 patients in the IA group and 44 patients in the control group. The log-rank test was used. The primary outcome was death from any cause. ESKD was defined as permanent renal-replacement therapy, including peritoneal dialysis, hemodialysis, and kidney transplantation. Remission was defined as a BVAS of 0. ESKD, end-stage kidney disease; IA, immunoadsorption; BVAS, Birmingham Vasculitis Activity Score.

\section{Clinical Assessment}

We obtained demographic data and laboratory examination data from the electronic medical record system. Birmingham Vasculitis Activity Score (BVAS) version 3 [30] was used to evaluate disease activity. The primary outcome was death from any cause, and the secondary outcomes were remission, ESKD, and relapse. ESKD was defined as permanent renal-replacement therapy, including peritoneal dialysis, hemodialysis, and kidney transplantation. Remission was defined as a BVAS of 0 (i.e., the absence of extrarenal manifestations of vasculitis, a stabilized or improved GFR, resolution of hematuria, and no active urinary sediment). The presence of proteinuria was not considered an indicator of disease activity. Relapse was defined as the increased disease activity with a BVAS $>0$ after remission.

Immunoadsorption Treatment in AAV with Severe Kidney Involvement

\section{Statistical Analysis}

Continuous variables were presented as mean \pm SD if they were conforming to normal distribution or as the median (25th-75th percentile) if non-normal distribution. Categorical variables were presented as a count (percentage). For comparison of variables, the $t$ test, Wilcoxon signed-rank test, Mann-Whitney $U$ test, and $\chi^{2}$ test or Fisher's exact test were appropriately used. Cumulative survival probabilities were calculated by the Kaplan-Meier method and were compared by the log-rank test between groups. Cox regression analysis was used to estimate the hazard ratios (HRs) and determine predictive factors for ESKD and death. Variables with $p<0.05$ in univariate analysis were included in multivariate analysis. Patients with missing data were excluded in some specified analyses. We performed all statistical analyses using IBM SPSS Statistics version 26.0 software (IBM Corp., Chicago, IL, USA). A 2 -tailed $p<0.05$ was considered statistically significant. 
Table 1. Characteristics of AAV patients with severe kidney involvement at baseline

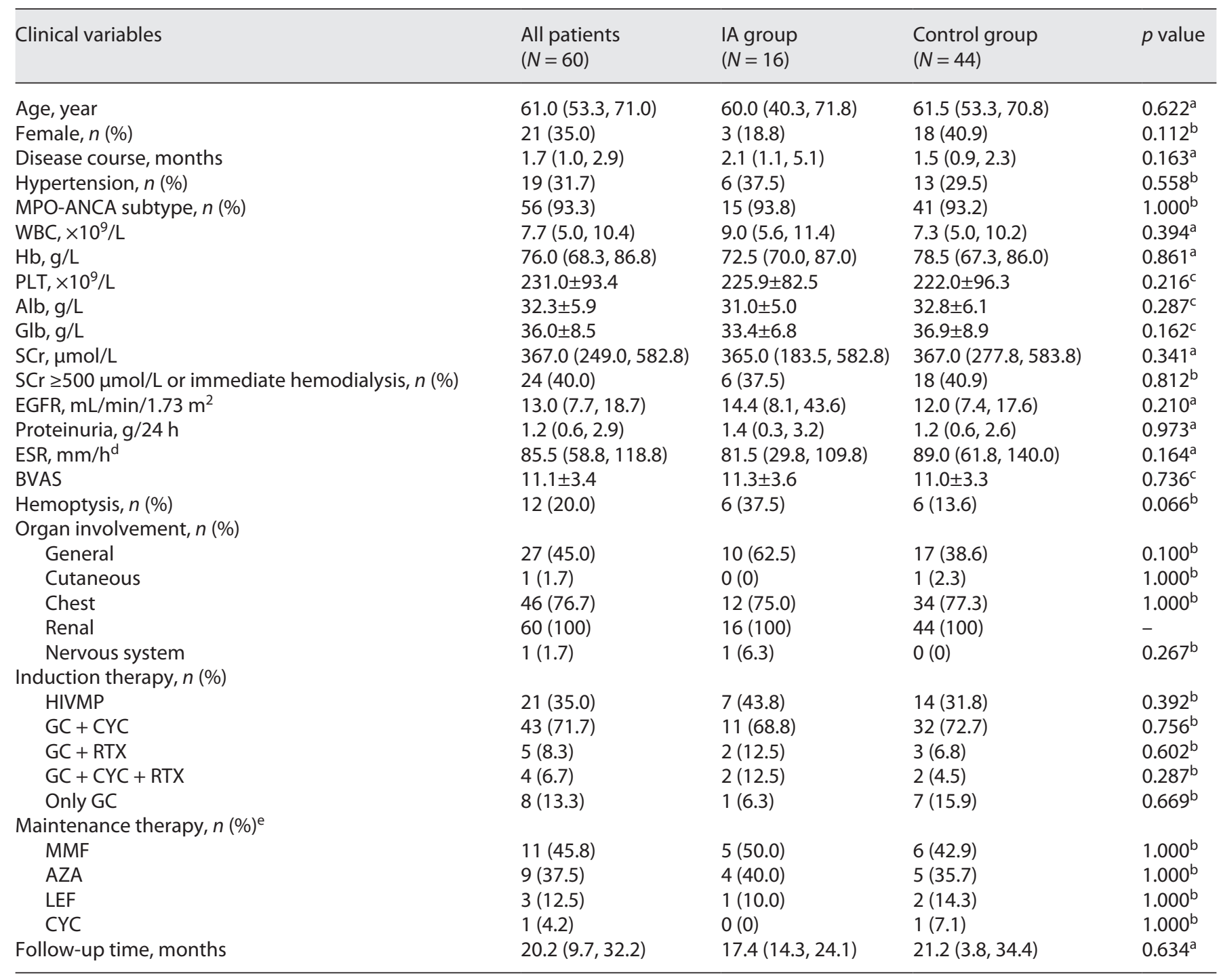

IA, immunoadsorption; MPO, myeloperoxidase; ANCA, antineutrophil cytoplasmic antibody; WBC, white blood cells; Hb, hemoglobin; PLT, platelet; Alb, albumin; Glb, globulin; SCr, serum creatinine; eGFR, estimation glomerular filtration rate; ESR, erythrocyte sedimentation rate; BVAS, Birmingham Vasculitis Activity Score; HIVMP, high-dose intravenous methylprednisolone; GC, glucocorticoid; CYC, cyclophosphamide; RTX, rituximab; MMF, mycophenolate mofetil; AZA, azathioprine; LEF, leflunomide; AAV, antineutrophil cytoplasmic antibody-associated vasculitis. ${ }^{a}$ Mann-Whitney U test. ${ }^{b} X^{2}$ test or Fisher's exact test. ${ }^{C}$ Independent sample $t$ test. ${ }^{d}$ The sample sizes of the IA group and control group were 16 and 38, respectively. ${ }^{\text {e }}$ The sample sizes of remission in the IA group and control group were 10 and 14 , respectively.

\section{Results}

\section{Baseline Characteristics}

The baseline characteristics were shown in Table 1, all of $p$ values $>0.05$. The median of age was 61.0 years, and 21 patients $(35.0 \%)$ were female. The median of disease course, from the onset of clinical manifestations to the initiation of therapy, was 1.7 months. Fifty-six patients (93.3\%) were positive for MPO-ANCA. The median of baseline SCr and eGFR was $367.0 \mu \mathrm{mol} / \mathrm{L}$ and $13.0 \mathrm{~mL} /$ $\min / 1.73 \mathrm{~m}^{2}$, respectively. Twenty-four patients (40.0\%) had SCr $\geq 500 \mu \mathrm{mol} / \mathrm{L}$ or needed immediate hemodialysis. Only 5 patients received renal biopsy. All patients had high disease activity with a baseline BVAS of $11.1 \pm 3.4$, 
Table 2. Cox regression analysis of risk factors predicting ESKD of AAV with severe kidney involvement

\begin{tabular}{|c|c|c|c|c|}
\hline \multirow[t]{2}{*}{ Variable } & \multicolumn{2}{|l|}{ Univariate analysis } & \multicolumn{2}{|c|}{ Multivariate analysis } \\
\hline & $\mathrm{HR}(95 \% \mathrm{Cl})$ & $p$ value & $\mathrm{HR}(95 \% \mathrm{Cl})$ & $p$ value \\
\hline Age (years) & $1.01(0.98-1.04)$ & 0.629 & - & - \\
\hline Male & $3.09(0.89-10.81)$ & 0.077 & - & - \\
\hline Disease course (months) & $0.96(0.78-1.17)$ & 0.672 & - & - \\
\hline $\mathrm{Glb}(\mathrm{g} / \mathrm{L})$ & $0.94(0.89-1.00)$ & 0.049 & $1.01(0.94-1.08)$ & 0.836 \\
\hline $\begin{array}{l}\mathrm{SCr} \geq 500 \mu \mathrm{mol} / \mathrm{L} \text { or immediate } \\
\text { hemodialysis }\end{array}$ & $5.76(2.01-16.53)$ & 0.001 & $5.77(1.61-20.72)$ & 0.007 \\
\hline Proteinuria (g/24 h) & $0.99(0.81-1.21)$ & 0.891 & - & - \\
\hline BVAS & $1.28(1.10-1.49)$ & 0.001 & $1.19(1.01-1.41)$ & 0.043 \\
\hline Added IA treatment & $0.68(0.22-2.11)$ & 0.508 & - & - \\
\hline Remission & $0.04(0.01-0.34)$ & 0.003 & $0.03(0.003-0.25)$ & 0.001 \\
\hline
\end{tabular}

Bold values are significant. HR, hazard ratio; $95 \% \mathrm{Cl}, 95 \%$ confidence interval; Glb, globulin; $\mathrm{SCr}$, serum creatinine; BVAS, Birmingham Vasculitis Activity Score; IA, immunoadsorption; AAV, antineutrophil cytoplasmic antibodyassociated vasculitis; ESKD, end-stage kidney disease.

and at least 1 organ was involved. Chest involvement occurred in 46 patients $(76.7 \%)$, and 12 patients $(20.0 \%)$ presented with hemoptysis. The follow-up time was 20.2 $(9.7,32.2)$ months.

\section{ANCA, BVAS, Ig, and C}

The frequency of IA was $5.1 \pm 1.8$. Fifteen patients in the IA group and 13 patients in the control group were detected with MPO-ANCA by enzyme-linked immunosorbent assay before and within 1 month after treatment (3-31 days, median 11 days). The values of MPO-ANCA before treatment were $175.4 \pm 82.2 \mathrm{RU} / \mathrm{mL}$ and $190.1 \pm$ $38.8 \mathrm{RU} / \mathrm{mL}$, respectively, in the IA group and control group ( $p=0.559$ ) (online suppl. Fig. 2a). Within 1 month after induction treatment, MPO-ANCA decreased significantly in both groups (online suppl. Fig. 2a). The values of MPO-ANCA decreased to $63.1 \pm 72.2 \mathrm{RU} / \mathrm{mL}$ and $142.4 \pm 75.7 \mathrm{RU} / \mathrm{mL}$, respectively, in the IA group and control group ( $p=0.010$ ) (online suppl. Fig. 2a). The reduction rate of MPO-ANCA in the IA group versus control group was $78.4(59.2,86.2) \%$ versus $9.3(7.2,59.0) \%$ $(p=0.005)$ (online suppl. Fig. 2b). In the first 6 months after treatment, the ANCA-positive percentage, detected by the indirect immunofluorescence assay, decreased gradually in both groups (online suppl. Fig. 2c). ANCApositive percentage in the IA group versus control group was $100.0 \%$ versus $97.7 \%$ before treatment $(p=1.000)$, $68.8 \%$ versus $94.7 \%$ after 1 month treatment $(p=0.019)$, $46.7 \%$ versus $77.1 \%$ after 3 -month treatment $(p=0.049)$, and $46.7 \%$ versus $58.1 \%$ after 6 -month treatment $(p=$ 0.538) (online suppl. Fig. 2c).

Immunoadsorption Treatment in AAV with Severe Kidney Involvement
BVAS, which reflected disease activity, decreased from $11.3 \pm 3.6-6.3 \pm 2.0, p<0.001$ and from $11.0 \pm 3.3-8.6 \pm$ $3.2, p<0.001$, respectively, in the IA group and control group (online suppl. Fig. 2d). The disease activity of IA group was lower than that of the control group after treatment ( $p=0.022$ ) (online suppl. Fig. $2 \mathrm{~d}$ ).

Compared to baseline, Ig and complements (Cs) were significantly reduced after IA treatment (online suppl. Fig. 3a). Reduction rates were $34.8 \pm 17.9 \%$ for IgA, 59.1 $\pm 28.7 \%$ for $\operatorname{IgG}, 35.5 \pm 24.1 \%$ for IgM, $47.7 \pm 20.9 \%$ for C3, and $52.3 \pm 26.5 \%$ for C4 (suppl. Fig. 3b). IA showed a significant advantage in IgG clearance compared with that of IgA and IgM. MPO-ANCA and IgG were detected in 2 patients before and after each session, which showed that the decline of MPO-ANCA was consistent with that of IgG with a downward trend (online suppl. Fig. 3c).

\section{Primary and Secondary Outcomes}

During follow-up, remission was achieved in $10 \mathrm{pa}-$ tients in the IA group and 14 patients in the control group. The cumulative remission rate in the IA group was higher than that in the control group ( $\mathrm{HR}=2.3,95 \% \mathrm{CI}$ : $1.1 \sim 7.2, p=0.033$ ) (Fig. 1a). Time to remission in the IA group and control group were $2.9 \pm 1.2$ months and $5.4 \pm$ 4.0 months, respectively ( $p=0.035)$. Cumulative remission rates at 6 months in the IA group and control group were $66.7 \%$ and $29.2 \%$, respectively. Four patients in the IA group and 13 patients in the control group developed ESKD. There was no difference in the cumulative rate of ESKD in both groups ( $\mathrm{HR}=0.7,95 \% \mathrm{CI}: 0.3 \sim 2.0, p=$ 
Table 3. Cox regression analysis of risk factors predicting death due to AAV with severe kidney involvement

\begin{tabular}{|c|c|c|c|c|}
\hline \multirow[t]{2}{*}{ Variable } & \multicolumn{2}{|c|}{ Univariate analysis } & \multicolumn{2}{|c|}{ Multivariate analysis } \\
\hline & $\mathrm{HR}(95 \% \mathrm{Cl})$ & $p$ value & $\mathrm{HR}(95 \% \mathrm{Cl})$ & $p$ value \\
\hline Age (years) & $1.08(1.03-1.14)$ & 0.001 & $1.08(1.02-1.13)$ & 0.004 \\
\hline Male & $1.41(0.58-3.42)$ & 0.455 & - & - \\
\hline Disease course (months) & $1.03(0.89-1.20)$ & 0.680 & - & - \\
\hline $\mathrm{Glb}(\mathrm{g} / \mathrm{L})$ & $1.02(0.97-1.07)$ & 0.385 & - & - \\
\hline $\begin{array}{l}\mathrm{SCr} \geq 500 \mu \mathrm{mol} / \mathrm{L} \text { or immediate } \\
\text { hemodialysis }\end{array}$ & $1.23(0.54-2.80)$ & 0.629 & - & - \\
\hline Proteinuria (g/24 h) & $0.81(0.61-1.09)$ & 0.163 & - & - \\
\hline BVAS & $1.01(0.89-1.14)$ & 0.901 & - & - \\
\hline Added IA treatment & $0.23(0.05-0.99)$ & 0.049 & $0.30(0.07-1.29)$ & 0.105 \\
\hline Remission & $0.04(0.01-0.33)$ & 0.002 & $0.07(0.01-0.51)$ & 0.009 \\
\hline
\end{tabular}

Bold values are significant. HR, hazard ratio; $95 \% \mathrm{Cl}, 95 \%$ confidence interval; Glb, globulin; $\mathrm{SCr}$, serum creatinine; BVAS, Birmingham Vasculitis Activity Score; IA, immunoadsorption; AAV, antineutrophil cytoplasmic antibodyassociated vasculitis.

0.504) (Fig. 1b). Twenty-three patients died, including 2 patients in the IA group and 21 patients in the control group during follow-up. A survival advantage was found in patients treated with IA compared with standard regimen (HR $=0.2,95 \%$ CI: $0.1 \sim 0.9, p=0.032$ ) (Fig. 1c). Cumulative death rates at 12 months in the IA group and control group were $6.3 \%$ and $36.3 \%$, respectively. When ESKD or death was identified as a composite endpoint, additional IA treatment was found to induce a better outcome (HR $=0.4,95 \%$ CI: 0.2 0.9, $p=0.049$ ) (Fig. 1d). After remission, 2 patients in the IA group relapsed, and 6 patients in the control group relapsed. There was no difference in the cumulative relapse rate in both groups (HR $=0.6,95 \%$ CI: $0.1 \sim 2.5, p=0.477)$.

\section{Risk Factors for ESKD and Death}

Univariate Cox regression analyses revealed the risk factors for ESKD (Table 2) and death (Table 3) in AAV patients with severe kidney involvement. Factors with $p<0.05$ in the univariate analysis were selected for multivariate Cox regression analysis. Multivariate Cox regression models indicated that $\mathrm{SCr} \geq 500 \mu \mathrm{mol} / \mathrm{L}$ or needed immediate hemodialysis at baseline ( $\mathrm{HR}=5.77,95 \%$ CI: $1.61 \sim 20.72, p=0.007)$, BVAS at baseline (HR $=1.19$, $95 \% \mathrm{CI}: 1.01 \sim 1.41, p=0.043)$, and remission $(\mathrm{HR}=0.03$, $95 \%$ CI: $0.003 \sim 0.25, p=0.001)$ were independent predictors for ESKD (Table 2). Age $(\mathrm{HR}=1.08,95 \% \mathrm{CI}$ : $1.02 \sim 1.13, p=0.004)$ and remission $(\mathrm{HR}=0.07,95 \% \mathrm{CI}$ : $0.01 \sim 0.51, p=0.009$ ) were independent predictive factors for death (Table 3 ).

\section{Tolerance}

IA treatment was well tolerated. Hypotension was observed during treatment in 4 patients in the IA group, which was corrected by supplementing albumin or saline and generally did not affect the treatment process. One patient presented with mild chest tightness during treatment and improved spontaneously. No allergy and other events were observed during treatment.

\section{GC, CYC, and Adverse Events}

In patients who achieved remission by GC and CYC (IA group $[N=8]$, control group $[N=13]$ ), steroids and immunosuppressors exposure levels and adverse events during follow-up were compared. When remission was achieved, the cumulative doses of GC and CYC in the IA group were lower than those in the control group, which were $3.6(2.0,4.6)$ g versus $4.7(3.8,6.7) \mathrm{g}(p=0.046)$ (online suppl. Fig. $4 \mathrm{a})$ and $1.3(0.8,2.0) \mathrm{g}$ versus $2.6(1.7,5.2)$ $\mathrm{g}(p=0.026)$ (online suppl. Fig. $4 \mathrm{~b})$, respectively. After treatment, the daily doses of GC were tapered in both groups, and the doses in the IA group were less than those in the control group after 1-month, 3-month, and 6 -month treatment $(p=0.049,0.040$, and 0.035$)$, respectively (online suppl. Fig. 4c). However, there was no difference in both groups after treatment $(p=0.116)$ and after 12-month treatment $(p=0.590)$.

In these patients, infection that occurred at any site was the most common adverse event, occurring in 7 patients $(87.5 \%)$ and 12 patients $(92.3 \%)$ in the IA group and control group, respectively $(p=1.000)$ (online suppl. Table 1). The frequency of infection in the IA group ver- 
sus control group was $1.3 \pm 0.9$ versus $2.2 \pm 1.0(p=0.048)$ and $1.8 \pm 1.6$ versus $2.5 \pm 1.2(p=0.256)$ in the first 6 months and 12 months after treatment, respectively. Severe infections that led to delays in CYC treatments occurred in 2 patients and 4 patients in the IA group and control group, respectively. Other adverse events had also been observed, but there were no differences between both groups (online suppl. Table 1).

\section{Discussion}

AAV with an acute onset is an acute and critical disease, threatening the health of kidneys. PLEX has been advocated as an adjunct therapy in AAV with kidney involvement. However, the prospective PEXIVAS trial [22] and the retrospective study at the Mayo Clinic [4] did not find the benefit of PLEX in improving prognosis of AAV patients with severe kidney diseases. IA selectively removes pathogenic Igs and retains protective plasma proteins, theoretically presenting a therapeutic advantage over nonselective PLEX. Therefore, we conducted this retrospective study to evaluate the outcomes of IA therapy in AAV patients with severe kidney involvement.

We found that the disease activity decreased more obviously in the IA group than the control group after treatment. In terms of MPO-ANCA clearance, IA showed superior over standard regimen $(78.4 \%$ vs. $9.3 \%)$ within 1 month after treatment. After IA treatment, the clearance rate of $\operatorname{IgG}(59.1 \pm 28.7 \%)$ was higher than that of $\operatorname{IgA}$ $(34.8 \pm 17.9 \%)$ and $\operatorname{IgM}(35.5 \pm 24.1 \%)$, and it was consistent with the changes of serum ANCA. The major isotype of ANCA is IgG, and this result well-reflected the characteristic of specific clearance of pathogenic antibodies by IA treatment, which was in line with previous reports [25-27]. We also found the superior ability of IA treatment in the decrease of $\mathrm{C} 3$ and $\mathrm{C} 4$. As the activation of the $\mathrm{C}$ system has been identified crucial for the development of AAV $[2,31]$, targeting the $\mathrm{C}$ system is a potential treatment strategy. It suggested that IA-related C clearance might also contribute to its renal protection.

We revealed that additional IA treatment induced quicker and higher remission. The majority of remission occurred in the first 6 months after treatment, in consistent with previous reports $[4,32,33]$. In the first 3 months, the ANCA-positive percentage was lower in the IA group than the control group. This indicated that the earlier negative turning of ANCA contributed to remission. However, our patients showed lower remission rates (control group, 44.5\% and IA group, 66.9\%) than that of previous studies from Western countries (70\%-90\%) treated with CYC and/or RTX [6]. The heterogeneity of race, disease activity, organ involvement, ANCA subtype, induction therapy, and the definition of remission might contribute to this difference. MPO-ANCA-positive vasculitis was dominant in Asian countries, such as Japan and China, with a positive percentage of $79 \%-93 \%$ [33, 34], such as that in our study. In a study from Chinese AAV patients treated with CYC, remission rate at 6 months was $47.1 \%$ [33], in line with that of our patients in the control group. Regarding a quicker and higher remission resulted from additional IA treatment, we should not only just be concerned about what was removed from patients but also what subsequent reaction happened in the body. It was reported that IA altered intracytoplasmic type 1 and type 2 T-cell cytokine productions [35]. A study about myasthenia gravis and Lambert-Eaton syndrome [36] demonstrated IA upregulated the anti-inflammatory factors (interleukin-10 [IL-10]) and reduce the pro-inflammatory factors (IL-17 and IL-18). Intravenous injection of purified staphylococcal protein $\mathrm{A}$ to healthy adult volunteers decreased peripheral lymphocyte counts as early as $8 \mathrm{~h}$, peaked at $24 \mathrm{~h}$, and returned to the baseline levels after 7 days [37]. Staphylococcal protein A was observed to bind to B cells in the splenic marginal zone inducing B-cell deletion [38-40]. Thus, apart from mechanically removing of toxic antibodies and Cs, IA might directly correct the impaired cellular and humoral immunity, which produce a more rapid response and higher clinical efficacy than those in the standard regimen.

We also found that added IA treatment reduced the occurrence of death. The cumulative death rate at 12 months was $36.3 \%$ in the control group, consistent with that of a study from Japan (28.9\%) [41], but IA therapy decreased the death rate to $6.3 \%$ in our study. Anyway, the frequency of total deaths $(38.3 \%, 23 / 60)$ is a little high in our cohort. The more severe pulmonary and kidney involvement may contribute to this difference. The causes of death were infections (52.2\%), active vasculitis (26.1\%), and others, in keeping with previous studies $[42,43]$. Two patients in the IA group died of infections rather than active vasculitis, suggesting a significant improvement of disease activity by IA therapy. However, we did not find an advantage in renal survival and reducing relapse with IA therapy in the follow-up period. Histopathological differences, various maintenance regimens, insufficient follow-up time, and small sample size may have led to this result. 
By multivariate Cox regression analysis, we found that the advantage of remission induced by IA treatment contributed to an improved prognosis. Remission was a significant independent ESKD-related and death-related predictor in AAV with severe kidney involvement. The Mayo Clinic's study [4] also showed that remission at 6 months was a predictor for ESKD or death at 18 months. Due to the lack of uniform ANCA quantitative titers and IgG values in some patients, we analyzed the association of globulin with outcomes. Although univariate analysis revealed that globulin was associated with ESKD, multivariate analysis did not find the predictive value of globulin. Patients with $S C r \geq 500 \mu \mathrm{mol} / \mathrm{L}$ or who needed immediate hemodialysis and patients with high BVASs at baseline have an increased risk of ESKD. Increasing age was an independent risk factor for death. Various markers of renal impairment, disease activity, and advanced age have also been found to be associated with a worse prognosis in previous studies $[32,43,44]$, which was consistent with our findings. In univariate analysis of factors predicting death, IA treatment was inversely associated with death.

Our study revealed no signs of intolerance during IA treatment. Hypotension was reported in a previous study [27] but did not lead to cessation of therapy. In our experience, adequate pre-flushing of the adsorption column prior to each session initiation to remove the protective fluid used to store the adsorbed column helped to prevent this undesirable side effect. In addition, chills, low-grade fever, musculoskeletal pain, nausea, and vomiting were also common adverse events of IA treatment [45], but none of these adverse events occurred in our observation. This may be due to the genetic engineering recombinant protein A column used in our study with a less toxic effect. Nevertheless, we should closely monitor the general situation of patients and deal with adverse events during the process of absorption.

Our study found that the advantage of earlier remission induced by IA treatment resulted in the reductions of steroids and immunosuppressor exposure doses. The infection frequency in the IA group was less than that in the control group in the first 6 months after treatment. However, there was no difference in infection frequency in the first 12 months after treatment and adverse events during follow-up. Thus, in the short term, reduced infections might also contribute to earlier remission in the IA group. But, it was not relying on reducing steroids and immunosuppressors exposure to improve the patients' long-term outcome. Due to these results from the limited sample size, a further validation is needed in a prospective, large sample study.
There were some limitations in this study. First, the sample size in this study was relatively small, especially in the IA group. Second, as a retrospective study, some data were missing. For example, the lacking of lymphocytes subsets prevented the analysis of changes in the immune system. Third, due to the lack of renal biopsy samples from the majority of participants, histopathological differences could not be excluded. Fourth, treatment regimens were not predetermined, being prone to selection bias based on the disease severity. Fifth, the duration of follow-up is not long enough to determine the difference in the risk of ESKD and relapse. A prospective, multicenter, large-sample, randomized controlled trial is needed in the future. Despite these limitations, to our knowledge, this was the first controlled study which directly compared the efficacy of IA and the standard regimen in AAV patients with severe kidney involvement.

In conclusion, IA treatment induced quicker and higher remission in AAV patients with severe kidney involvement and reduced mortality. Remission was a significant independent predictor for ESKD and death. Thus, before a more promising strategy for remission induction appears, IA should be considered as an initial therapeutic choice for AAV patients with severe kidney involvement.

\section{Acknowledgments}

We thank all patients for their participation in this study.

\section{Statement of Ethics}

This study was reviewed and approved by the Ethics Committee of Tongji Hospital affiliated with the Tongji Medical College of Huazhong University of Science and Technology, approval number TJ-IRB20181107. Informed consent was obtained from all patients.

\section{Conflict of Interest Statement}

All the authors have nothing to disclose.

\section{Funding Sources}

This work was supported by the Guangdong Provincial Key Laboratory of Hemoadsorption Technology Open Fund (2020KC001), the Guangzhou Koncen Bioscience Co. Ltd (Grants $2020100 ; 2021065)$ and the National Natural Science Foundation of China (Grants 81770681, 81974086, 81770684, 81974087). 


\section{Author Contributions}

Rui Zeng and Ying Yao contributed to the research idea and study design; Xiaoxin Chu, Yu Hong, Yuxi Wang, Chong Yu, Lisheng Wang, Hui Tong, Jianjun Yan, Zhonghua Zhang, and Gang $\mathrm{Xu}$ contributed to data acquisition, analysis, or interpretation; Xiaoxin Chu performed statistical analysis and wrote the paper; and Rui Zeng and Ying Yao contributed to supervision or mentorship. Rui Zeng and Ying Yao contributed equally to this work. All the authors have critically reviewed the manuscript and approved the final version.

\section{Data Availability Statement}

The data of this study are available from the corresponding author on reasonable request.

\section{References}

1 Jones RB, Tervaert JW, Hauser T, Luqmani R, Morgan MD, Peh CA, et al. Rituximab versus cyclophosphamide in ANCA-associated renal vasculitis. N Engl J Med. 2010 Jul 15; 363(3):211-20.

2 Geetha D, Jefferson JA. ANCA-associated vasculitis: core curriculum 2020. Am J Kidney Dis. 2020 Jan;75(1):124-37.

3 Kitching AR, Anders HJ, Basu N, Brouwer E, Gordon J, Jayne DR, et al. ANCA-associated vasculitis. Nat Rev Dis Primers. 2020 Aug 27; 6(1):71.

4 Casal Moura M, Irazabal MV, Eirin A, Zand L, Sethi S, Borah BJ, et al. Efficacy of rituximab and plasma exchange in antineutrophil cytoplasmic antibody-associated vasculitis with severe renal disease. J Am Soc Nephrol. 2020 Aug 21.

5 de Joode AA, Sanders JS, Stegeman CA. Renal survival in proteinase 3 and myeloperoxidase ANCA-associated systemic vasculitis. Clin J Am Soc Nephrol. 2013 Oct;8(10):1709-17.

6 Stone JH, Merkel PA, Spiera R, Seo P, Langford CA, Hoffman GS, et al. Rituximab versus cyclophosphamide for ANCA-associated vasculitis. N Engl J Med. 2010 Jul 15;363(3):221-32.

7 Mukhtyar C, Guillevin L, Cid MC, Dasgupta B, de Groot K, Gross W, et al. EULAR recommendations for the management of primary small and medium vessel vasculitis. Ann Rheum Dis. 2009 Mar;68(3):310-7.

8 de Groot K, Harper L, Jayne DR, Flores Suarez LF, Gregorini G, Gross WL, et al. Pulse versus daily oral cyclophosphamide for induction of remission in antineutrophil cytoplasmic antibody-associated vasculitis: a randomized trial. AnnIntern Med. 2009 May 19;150(10): 670-80.

9 Jones RB, Ferraro AJ, Chaudhry AN, Brogan P, Salama AD, Smith KG, et al. A multicenter survey of rituximab therapy for refractory antineutrophil cytoplasmic antibody-associated vasculitis. Arthrit Rheumat. 2009 Jul;60(7): 2156-68.

10 Walsh M, Jayne D. Rituximab in the treatment of anti-neutrophil cytoplasm antibody associated vasculitis and systemic lupus erythematosus: past, present and future. Kidney Int. 2007 Sep;72(6):676-82.
11 Smith KG, Jones RB, Burns SM, Jayne DR Long-term comparison of rituximab treatment for refractory systemic lupus erythematosus and vasculitis: Remission, relapse, and re-treatment. Arthritis Rheum. 2006 Sep; 54(9):2970-82.

12 Keogh KA, Wylam ME, Stone JH, Specks U. Induction of remission by B lymphocyte depletion in eleven patients with refractory antineutrophil cytoplasmic antibody-associated vasculitis. Arthritis Rheum. 2005 Jan;52(1): 262-8.

13 Specks U, Merkel PA, Seo P, Spiera R, Langford CA, Hoffman GS, et al. Efficacy of remission-induction regimens for ANCA-associated vasculitis. N Engl J Med. 2013 Aug 1; 369(5):417-27.

14 Nachman PH, Hogan SL, Jennette JC, Falk RJ. Treatment response and relapse in antineutrophil cytoplasmic autoantibody-associated microscopic polyangiitis and glomerulonephritis. J Am Soc Nephrol. 1996 Jan;7(1):33-9.

15 Reinhold-Keller E, Beuge N, Latza U, de Groot K, Rudert H, Nölle B, et al. An interdisciplinary approach to the care of patients with Wegener's granulomatosis: long-term outcome in 155 patients. Arthrit Rheum. 2000 May;43(5):1021-32.

16 Booth AD, Almond MK, Burns A, Ellis P, Gaskin G, Neild GH, et al. Outcome of ANCA-associated renal vasculitis: a 5-year retrospective study. Am J Kidney Dis. 2003 Apr; 41(4):776-84

17 Kronbichler A, Shin JI, Wang CS, Szpirt WM, Segelmark M, Tesar V. Plasma exchange in ANCA-associated vasculitis: the pro position. Nephrol Dial Transplant. 2021 Jan 25;36(2): 227-31.

18 Specks U, Fussner LA, Cartin-Ceba R, Casal Moura M, Zand L, Fervenza FC. Plasma exchange for the management of ANCA-associated vasculitis: the con position. Nephrol Dial Transplant. 2021 Jan 25;36(2):231-6.

19 Jayne DR, Gaskin G, Rasmussen N, Abramowicz D, Ferrario F, Guillevin L, et al. Randomized trial of plasma exchange or high-dosage methylprednisolone as adjunctive therapy for severe renal vasculitis. J Am Soc Nephrol. 2007 Jul;18(7):2180-8.
20 Walsh M, Casian A, Flossmann O, Westman K, Hoglund P, Pusey C, et al. Long-term follow-up of patients with severe ANCA-associated vasculitis comparing plasma exchange to intravenous methylprednisolone treatment is unclear. Kidney Int. 2013 Aug;84(2):397-402.

21 Walsh M, Merkel PA, Peh CA, Szpirt W, Guillevin L, Pusey CD, et al. Plasma exchange and glucocorticoid dosing in the treatment of anti-neutrophil cytoplasm antibody associated vasculitis (PEXIVAS): protocol for a randomized controlled trial. Trials. 2013 Mar 14;14: 73.

22 Walsh M, Merkel PA, Peh CA, Szpirt WM, Puéchal X, Fujimoto S, et al. Plasma Exchange and Glucocorticoids in Severe ANCA-Associated Vasculitis. N Engl J Med. 2020 Feb 13; 382(7):622-31.

23 Dorst J, Fangerau T, Taranu D, Eichele P, Dreyhaupt J, Michels S, et al. Safety and efficacy of immunoadsorption versus plasma exchange in steroid-refractory relapse of multiple sclerosis and clinically isolated syndrome: A randomised, parallel-group, controlled trial. EClinicalMedicine. 2019 Nov; 16:98-106.

24 Stummvoll GH. Immunoadsorption (IAS) for systemic lupus erythematosus. Lupus. 2011 Feb;20(2):115-9.

25 Palmer A, Cairns T, Dische F, Gluck G, Gjorstrup P, Parsons V, et al. Treatment of rapidly progressive glomerulonephritis by extracorporeal immunoadsorption, prednisolone and cyclophosphamide. Nephrol Dial Transplant. 1991;6(8):536-42.

26 Esnault VL, Testa A, Jayne DR, Soulillou JP, Guenel J. Influence of immunoadsorption on the removal of immunoglobulin $\mathrm{G}$ autoantibodies in crescentic glomerulonephritis. Nephron. 1993;65(2):180-4.

27 Matic G, Michelsen A, Hofmann D, Winkler $\mathrm{R}$, Tiess M, Schneidewind JM, et al. Three cases of C-ANCA-positive vasculitis treated with immunoadsorption: possible benefit in early treatment. Ther Apher. 2001 Feb;5(1):68-72.

28 Jennette JC, Falk RJ, Bacon PA, Basu N, Cid $\mathrm{MC}$, Ferrario F, et al. Revised international chapel hill consensus conference nomenclature of vasculitides. Arthrit Rheum. 2013 Jan; 65(1):1-11.
Immunoadsorption Treatment in AAV with Severe Kidney Involvement 
29 Levey AS, Stevens LA, Schmid CH, Zhang YL, Castro AF 3rd, Feldman HI, et al. A new equation to estimate glomerular filtration rate. Ann Intern Med. 2009 May 5;150(9):604-12.

30 Mukhtyar C, Lee R, Brown D, Carruthers D, Dasgupta B, Dubey S, et al. Modification and validation of the Birmingham vasculitis activity score (version 3). Ann Rheum Dis. 2009 Dec;68(12):1827-32.

31 Chen M, Jayne DRW, Zhao MH. Complement in ANCA-associated vasculitis: mechanisms and implications for management. Nat Rev Nephrol. 2017 Jun;13(6):359-67.

32 Mukhtyar C, Flossmann O, Hellmich B, Bacon P, Cid M, Cohen-Tervaert JW, et al. Outcomes from studies of antineutrophil cytoplasm antibody associated vasculitis: a systematic review by the European League Against Rheumatism systemic vasculitis task force. Ann Rheum Dis. 2008 Jul;67(7):100410.

33 Hu W, Liu C, Xie H, Chen H, Liu Z, Li L. Mycophenolate mofetil versus cyclophosphamide for inducing remission of ANCA vasculitis with moderate renal involvement Nephrol Dial Transplant. 2008 Apr;23(4): 1307-12.

34 Fujimoto S, Uezono S, Hisanaga S, Fukudome K, Kobayashi S, Suzuki K, et al. Incidence of ANCA-associated primary renal vasculitis in the Miyazaki Prefecture: the first populationbased, retrospective, epidemiologic survey in Japan. Clin J Am Soc Nephrol. 2006 Sep; 1(5): 1016-22.
35 Hehmke B, Salzsieder E, Matic GB, Winkler RE, Tiess M, Ramlow W. Immunoadsorption of immunoglobulins alters intracytoplasmic type 1 and type $2 \mathrm{~T}$ cell cytokine production in patients with refractory autoimmune diseases. Ther Apher. 2000 Aug;4(4):296-302.

36 Baggi F, Ubiali F, Nava S, Nessi V, Andreetta F, Rigamonti A, et al. Effect of IgG immunoadsorption on serum cytokines in MG and LEMS patients. J Neuroimmunol. 2008 Sep 15;202:104-10.

37 Ballow C, Leh A, Slentz-Kesler K, Yan J, Haughey D, Bernton E. Safety, pharmacokinetic, immunogenicity, and pharmacodynamic responses in healthy volunteers following a single intravenous injection of purified staphylococcal protein A. J Clin Pharmacol. 2013 Sep;53(9):909-18.

38 Goodyear CS, Silverman GJ. Staphylococcal toxin induced preferential and prolonged in vivo deletion of innate-like B lymphocytes. Proc Natl Acad Sci USA. 2004 Aug 3;101(31): 11392-7.

39 Silverman GJ, Cary SP, Dwyer DC, Luo L, Wagenknecht R, Curtiss VE. A B cell superantigen-induced persistent "Hole" in the B-1 repertoire. J Exp Med. 2000 Jul 3;192(1):8798.
40 Goodyear CS, Silverman GJ. Death by a B cell superantigen: In vivo $\mathrm{VH}$-targeted apoptotic supraclonal B cell deletion by a Staphylococcal Toxin. J Exp Med. 2003 May 5;197(9): 1125-39.

41 Kawai H, Banno S, Kikuchi S, Nishimura N, Nobata H, Kimura Y, et al. Retrospective analysis of factors predicting end-stage renal failure or death in patients with microscopic polyangiitis with mainly renal involvement. Clin Exp Nephrol. 2014 Oct;18(5):795-802.

42 Garcia-Vives E, Segarra-Medrano A, Martinez-Valle F, Agraz I, Solans-Laque R. Prevalence and risk factors for major infections in patients with antineutrophil cytoplasmic antibody-associated vasculitis: influence on the disease outcome. J Rheumatol. 2020 Mar; 47(3):407-14.

43 Flossmann O, Berden A, de Groot K, Hagen C, Harper L, Heijl C, et al. Long-term patient survival in ANCA-associated vasculitis. Ann Rheum Dis. 2011 Mar;70(3):488-94.

44 Gayraud M, Guillevin L, le Toumelin P, Cohen P, Lhote F, Casassus P, et al. Long-term followup of polyarteritis nodosa, microscopic polyangiitis, and Churg-Strauss syndrome: analysis of four prospective trials including 278 patients. Arthrit Rheum. 2001 Mar;44(3): 666-75.

45 Messerschmidt GL, Henry DH, Snyder HW Jr, Bertram J, Mittelman A, Ainsworth S, et al. Protein A immunotherapy in the treatment of cancer: an update. Semin Hematol. 1989 Apr; 26(1):19-24 